\title{
SELECTED MODERN METHODS AND TOOLS FOR PUBLIC PARTICIPATION IN URBAN PLANNING - A REVIEW
}

\author{
Muki HaKlay ${ }^{1}$, Piotr JanKowSKI ${ }^{2,3}$, ZBigniew ZwolińSKI ${ }^{3}$ \\ ${ }^{1}$ Department of Geography, University College London, United Kingdom \\ ${ }^{2}$ Department of Geography, San Diego State University, USA \\ ${ }^{3}$ Institute of Geoecology and Geoinformation, Adam Mickiewicz University in Poznań, Poland
}

Manuscript received: August 17, 2017

Revised version: August 20, 2018

\begin{abstract}
Haklay M., JANKOWSKi P., Zwoliński Zв., 2018. Selected modern methods and tools for public participation in urban planning - a review. Quaestiones Geographicae 37(3), Bogucki Wydawnictwo Naukowe, Poznań, pp. 127-149, 15 figs, 2 tables.

ABSTRACT: The paper presents a review of contributions to the scientific discussion on modern methods and tools for public participation in urban planning. This discussion took place in Obrzycko near Poznan, Poland. The meeting was designed to allow for an ample discussion on the themes of public participatory geographic information systems, participatory geographic information systems, volunteered geographic information, citizen science, Geoweb, geographical information and communication technology, Geo-Citizen participation, geo-questionnaire, geo-discussion, GeoParticipation, Geodesign, Big Data and urban planning. Participants in the discussion were scholars from Austria, Brazil, the Czech Republic, Finland, Ireland, Italy, the Netherlands, Poland, the United Kingdom, and the USA. A review of public participation in urban planning shows new developments in concepts and methods rooted in geography, landscape architecture, psychology, and sociology, accompanied by progress in geoinformation and communication technologies. The discussions emphasized that it is extremely important to state the conditions of symmetric cooperation between city authorities, urban planners and public participation representatives, social organizations, as well as residents.
\end{abstract}

KEY WORDS: Geoweb methods, public participation, urban planning, GIScience, citizen science

Corresponding author: Zbigniew Zwoliński, ZbZw@amu.edu.pl

\section{Introduction}

Researchers and practitioners of urban planning have had a variable interest in developing and applying methods of public participation since the 1970s. The interest in methods accelerated in the mid-1990s, accompanied by the developments in public participation geographic information systems (PPGIS) and participatory GIS (PGIS). The arrival of Web 2.0 in the 2000s and improvements in geographic information technologies resulted in the proliferation of geographically related tools and Web services (Geoweb) for individuals and groups. Developments in P/ PGIS, volunteered geographic information (VGI), and Geoweb have been recently paralleled by the growth of holistic approach to public participation in urban planning exemplified by Geodesign - a process relying on digital geographic methods and tools for integrating analysis, evaluation, design and public involvement in urban and regional planning. Despite much interest in participatory methods rooted in mapping and visualisation of geographical data, there has not been many opportunities for scholars working at the intersection of participatory methods, communication technologies, and urban planning to meet sharing their research and learning from one another.

The aim of this paper is a review of contributions to the scientific discussion on modern methods and tools for public participation in 
urban planning. This discussion took place in the Raczyński's Palace in Obrzycko near Poznań, on $22^{\text {nd }}$ and $23^{\text {rd }}$ of June 2017. Piotr Jankowski opened the meeting explaining the background of the discussion panel, explaining a project realised at the Adam Mickiewicz University on participatory GIS in urban planning. The meeting was designed to allow for an ample discussion on the themes of participatory GIS, citizen science, VGI, Geodesign and urban planning.

\section{0 years of public participation GIS research and practice in Finland}

Marketta Kyttä (Aalto University, Finland) delivered the keynote address to start the discussion. She talked about 10 years of public participation GIS research and practice in Finland, reflecting on the experience since 2000. Drawing from her background in environment psychology she has been interested in the human side of GIS technology and in testing the veracity of claims that tacit and experiential knowledge cannot be integrated into design and practice. In the 1990s, she felt that environmental psychology was focusing on the person, individual feelings and perceptions, but forgetting about the environment. She believed that the interaction between the environment and the person was generating experiences, and there were only a few approaches addressing this relationship - among them Wohlwill (1973), pointing out that the environment is not in the head. Her work let her to conceive of place-based approach to GIS, which she termed softGIS - to underscore a behavioural approach to utilizing GIS in order to study human behaviour and experience in the physical environment. The concept of softGIS was motivated by thinking about how to link perceptions and emotions and the different ways of understanding space through the lens of a physical location. The new methodology was conceived in 2003 and the first prototype was developed in 2005, but the technology was weak. The development then progressed to softGIS survey tools, which were more robust technically, but each survey required a lot of effort. The survey tools eventually evolved into Maptionnaire ${ }^{\mathrm{TM}}$ service that has made possible since 2015 to use the tools in a more structured way. The Maptionnaire ${ }^{\mathrm{TM}}$ software, which is now maintained and offered by a private company, has been used in projects in the Nordic countries, Japan, USA, and in many other places. Through the literature, M. Kyttä discovered relevant areas which she was unaware of at the beginning of her work leading to softGIS methodology - PGIS, PPGIS, Citizen Science, VGI. Her work is the nearest to the work of Greg Brown form California Polytechnic State University conceptually and structurally there are many similarities in the methodology used by both of them. She sees the person-environment relationship and participatory planning as yin and yang - they contribute to each other. In her research she has looked at social sustainability, mobility, and environmental memories across different groups - from children to elderly. She has also investigated human-environment relationship at different scales, various planning stages, and in various planning approaches. M. Kyttä and her group have done over 70 research projects using place-based research approach and over 150 participatory planning projects.

The case studies carried out between 20132017 show the majority of them were done in real-world planning situations with much less in research. The common reality of public participation is that those who show up in open meetings have negative views. There are some people who are the activists passionate about a particular issue or values. There needs to be an alternative way of engaging people who are less assertive. The Finnish law has mandated participatory planning since 2000, but the planning practice has been slow to change; only a handful of people participate, the deployment of participation tools has been slow to come, the influence of participation on planning decision-making has been minimal, the focus of those who participate has been on resisting changes, data collected in the course of participation has been invisible, and participatory processes have been demanding much effort of the organisers and participants. In Finish case studies, a PPGIS in the form of a questionnaire tool has been used as a crowdsourcing tool in urban planning. The pros are data volume and usability fostering collaborative participation. The cons include the issue of digital exclusion, data quality, and planning practices regarding the use of the information. 


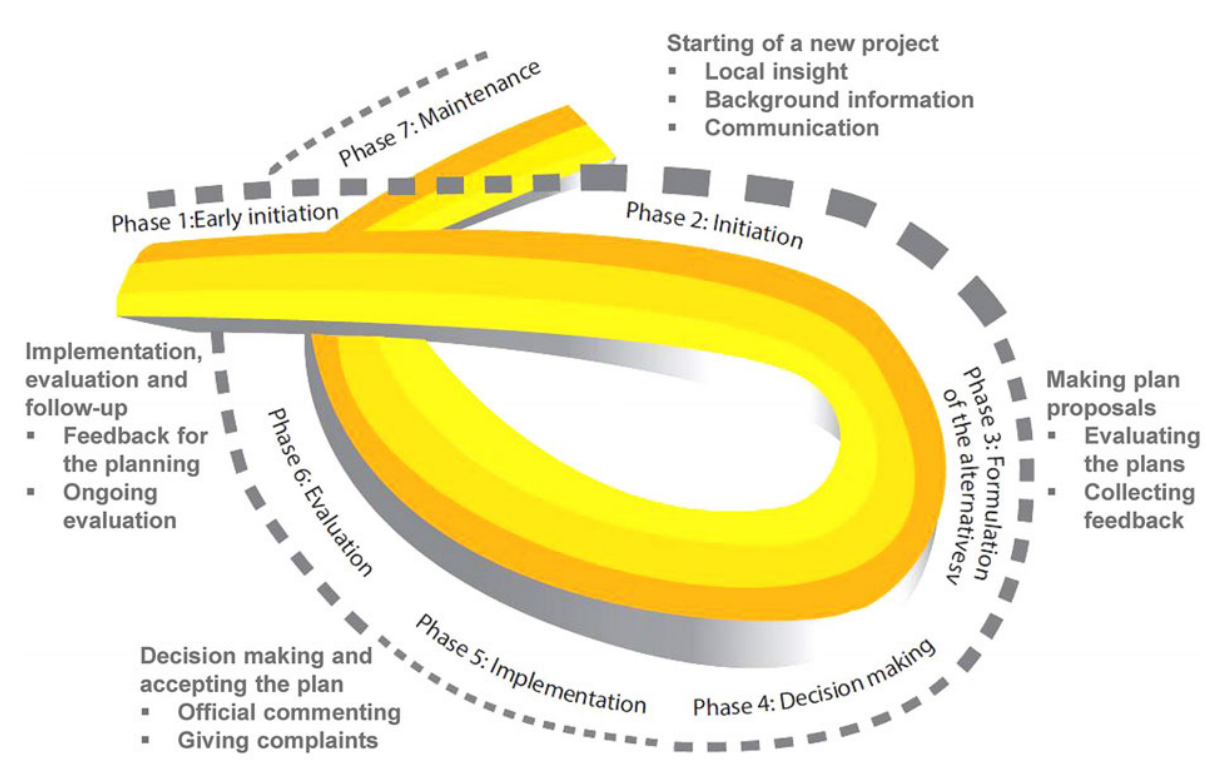

Fig. 1. Public participation support system by Kahila-Tani (2016).

Data volume online allows collecting large datasets with little effort and facilitates inclusiveness - wider groups of people that can be reached $(2,100$ participants who provided their input on water management plan in Helsinki and 3,750 people responded to Helsinki Master Plan survey providing 33,000 place marking), the representativeness looks good across demographic classes although it is tempered by the level of education. There is also an ability to customize the same tool in different languages and with different interface features, and reach different ethnic groups, children and young people. Children can provide good quality data.

The issue of data quality leading to actionable (planning) knowledge has been investigated by Kahila-Tani (2016) who considered how the relationship between individual participation and collective participation impacts the ability to maintain the diversity of opinion, individual independence, decentralisation, but also the need for data aggregation. The maps allow a new type of knowledge in a visible format - such as the location of a new building and green areas. Moreover, digital maps allow the analysis of green structures and their relationship to places where people live including the use of green structures that can be accounted for by performing simple spatial analysis operations like buffering and calculating usage densities. This approach allows to overlay an urban structure with behavioural and experiential factors, and then link them with health and wellbeing indicators to create explanatory models. For example, an analysis performed in Finland in one particular city established that as urban density increases the perceived environmental quality if it brings the everyday services closer. In the suburbs, however, the closer the services were, the lower was the perceived environmental quality. Why is this happening in the suburbs is an open question. The strength of PPGIS is that it allows for exploring this and other questions in different spatial context.

Is it possible to foster deep collaboration with PPGIS? The Maptionnaire ${ }^{\mathrm{TM}}$ tool allows the creation of geographical survey, in which questions are linked with places on a map. Reaching out to participants can be done by a representative sample, or more opportunistic approaches such as online advertising, or through a specific event. In a model of public-participation support system (Fig. 1) proposed by Kahila-Tani (2016) different process stages have different participation potential with the initiation phase being the essential step for the remainder of participatory process.

Is public participation influential in terms of impacting decision processes? In the Helsinki master plan it was possible to see the impact of suggestions offered by the public as the plan was published on a grid, and it was possible to compare it to the public survey, which showed that about $25 \%$ of the areas that people wanted to protect were threatened by the plan. PPGIS can also be integrated into existing systems, which has been demonstrated in the City of Lahti. 
The issues affecting PPGIS include:

- the use of digital technology: digital divide, technology stress that exists among older participants - people over 80 year of age, addressing problems in the redesign of application;

- it is important to see PPGIS in addition to deliberative processes that are linked to PPGIS data - people sometimes pointed out that PPGIS data was wrong as it did not represent their opinion;

- there are issues of data quality: representativeness, cherry picking, user privacy, manipulation, and skills required to effectively use the data. The data from the Helsinki participatory process, for example, was over-represented in the group of 20-40 year old. Moreover, the issue of representativeness is not only about demography but also about the opportunity;

- there are also ineffective planning practices: the lack of willingness to allow participation or influence, challenges in integrating the data into practice, and also an issue with surveys; namely that they is a continuation of topdown participation. There is a potential demand for surveys co-created by planners and the public and co-analysed data sets. There are no good examples for this and that is a future challenge. The danger in not responding to this challenge is PPGIS can be used as a therapeutic participatory device.

There are pros (data volume, actionable knowledge, fostering collaborative and influential participation) and cons (problems regarding access to and effective use of digital technology, data quality, ineffective planning practices) of using PPGIS as a crowdsourcing tool in urban planning. We can think about smart participation using social media - Foursquare, Instagram, OpenStreetMap or Twitter - but we need to think about how to make them work. In doing so, we should engage high-quality GIS knowledge from people who can support smart, human-friendly urban planning.

\section{Examining the values embedded in the processes and technologies of participatory GIS}

Muki Haklay (University College London, United Kingdom) in his talk started with noting that a persistent question about participatory methodologies that rely on technologies, such as public participation geographic information systems, is how to integrate values, such as inclusiveness of all the people who are impacted by a decision, or identifying options that are popular with the majority but acceptable to the minority, within technologically focused projects. Moreover, technologies do not operate by themselves - they are embedded in organisational, political, and social processes that determine how they are used, who can use them, and in what context. Therefore, we should explore the question of where the values reside. Two factors obscure our view. One is the misleading conceptualisation that technologies are value free, and can be used for good or for bad - which puts all the weight on the process and ignores the way, in which any technology allows only certain actions to be taken. Another popular view of technology conceptualisation is to emphasise its advantages (upside) and ignore its limitations. If we move beyond these, and other common sense views of technologies, we can notice how process and technology intertwine.

We can, therefore, look at the way the process/technology reinforce and limit each other, and the way that the values are integrated and influence them. With this analysis, we can also consider how technological development can explicitly include considerations of values, and be philosophically, politically, and social theory-informed (Fig. 2). We need to consider the roles, skills, and knowledge of the people that are involved in each part of the process - from community facilitation to software development.

\begin{tabular}{|l|l|l|}
\hline Technology is: & Autonomous & Humanly Controlled \\
\hline $\begin{array}{l}\text { Neutral (complete } \\
\text { separation of means and ends) }\end{array}$ & $\begin{array}{l}\text { Determinism } \\
\text { (traditional Marxism) }\end{array}$ & $\begin{array}{l}\text { Instrumentalism (liberal } \\
\text { faith in progress) }\end{array}$ \\
\hline $\begin{array}{l}\text { Value-laden } \\
\text { (means form a way of life that } \\
\text { includes ends) }\end{array}$ & $\begin{array}{l}\text { Substantivism (means and } \\
\text { ends linked in a system) }\end{array}$ & $\begin{array}{l}\text { Critical Theory (choice of } \\
\text { alternative means-ends } \\
\text { systems) }\end{array}$ \\
\hline
\end{tabular}

Fig. 2. M. Haklay's interpretation of Freenberg's (1999) opinion on technology. 
This line of inquiry draws on the experience of developing participatory geographic information technologies over the past 20 years (Participatory Rural Appraisal and Participatory Learning and Action in 1980s, Public Participation GIS and Participatory GIS in 1990s, Volunteered/ Crowdsourced Geographic Information and Participatory Sensing in 2000s, as well as Citizen Science in 2010s) and will suggest future directions for value-based participatory technology development (Experimenting with maps and Tap\&Map).

From the start, PPGIS has been both limited and enabled by technological aspects: hardware, software, data, and network speed. The Public Participation part means that it is embedded in complex and detailed social practices, thus making PPGIS a socio-technical practice. PPGIS is a valued-laden practice. Moreover, PPGIS is mostly about expressing the values. Values in PPGIS are the following: ensuring societal benefits from technology (Obermeyer 1998), respecting lay, local and traditional knowledge (Talen 1999), community, collective views, addressing inequities (Ghose 2001), maintaining scientific standards, ensuring quality, empowerment (Laituri 2003), supporting wider societal and environmental goals (Sieber 2004), democratisation (Dunn 2007), representation, giving voice (Kwan 2008), and inclusion: passive or assertive (Gottwald et al. 2016).

In summary, M. Haklay concluded that PPGIS is a socio-technical, value-laden process and practice. Values in PPGIS should be expressed in the social practices and in the technologies that are used. Generic technologies can be used, with some compromises and trade-offs but developing technologies also requires compromises and trade-offs.

\section{Formal ontologies to support participatory urban planning through the prism of roles theory}

Alessia Calafiore (University of Torino, Italy) covered in her talk aspects of FirstLife ${ }^{1}$ which is about collecting knowledge through crowdsourcing and then using it in support of

firstlife.org informed urban planning. The aim is collecting information about places and representation of places. A practical concern in GIS is to make explicit the assumption about daily experiences conditioned by place and location. How is place spatially constructed? Just like people's behaviour is often unexpected, so can places be used in unexpected ways. In an ontological analysis, A. Calafiore tries to represent spatially located social practices. Urban artefacts are interacting with people through social practices. Cities can be seen as complex interacting systems of urban artefacts (i.e. buildings, streets and parks) and spatially situated social practices. She is developing her concept based on the DOLCE ontological framework. Urban artefacts are subject to constraints, of which some can be negotiated and some are rigid. A social place is a non-rigid aspect of space and can by analysed by employing social roles theory for this aspect. Social practices can be analysed with predicate logic. Depending on whether social practices, in which an urban artefact participates, are compliant or not with its design specifications, a formal or informal social place emerges. If the social practice is compliant with the intended uses given by the very design specifications, then the urban artefact is playing a formal role. On the contrary, if the social practice is not compliant with the intended uses given by the design specifications, the urban artefact is playing an informal role.

\section{G-ICT and creative thinking in the context of urban resilience}

Aoife Corcoran (co-author Zorica NedovicBudic), (University College Dublin, Ireland) talked about the role of geographical information and communication technology (ICT) in creative thinking in urban planning, based on the result of Transitioning to Urban Resilience and Sustainability (TURAS) project ${ }^{2}$ she worked on with Zorica Nedovic-Budic (2012-2016). She specifically focused on how ICT tools, including PPGIS, can be used to improve urban resilience on the example this project and three case studies including: Reusing Dublin ${ }^{3}$, Meadows

turas-cities.org

www.reusingdublin.ie 
Timeline, and TwitterGI. Examples of urban resilience improvements include flooding readiness, increase of green infrastructure in inner cities or beneficial use of empty spaces. To start making resilience improvements, cities need to build a capacity for change. Social-ecological resilience is the ability to adapt and transform as a result of a change. In her research on urban resilience, A. Corcoran uses mixed-methods and a case-study approach to examine if geospatial information and communication technologies (G-ICT) can address cities' capacity for change and in doing so support the building of urban resilience and sustainability.

Her three cases looked at empty places in Dublin, community history and interventions in the Meadows Community in Nottingham, and supporting researchers on urban resilience at University of East London. In each case, she carried out a focus group with different stakeholders and ran different tests (Table 1). In Dublin, Reusing Dublin provided 400 entries about different locations that can be used, and in Nottingham, a geographic timeline about the history of an estate. In London, it was information from Twitter that can assist researchers. The analysis of these cases revealed that some of the technologies helped in creating new ideas, but A. Corcoran also realised that a co-creation process was quite central. The data alone is not enough to generate new ideas but requires a more deliberative project - said A. Corcoran. The mutability of technology is important - Reusing Dublin, for example, is being used by a homeless charity to raise awareness and collect data that can be used to lead to a change. Citizens + Data $=$ Change, albeit with awareness and joint effort. A.Corcoran is now setting up the "space engagers" social enterprise to address some space-related issues in different communities in Ireland. By having people engaged for a short time, geospatial technologies will allow people to get involved in coming up with ideas or contribute to wider social goods - she said.

\section{Engineering for the local systems of the social participation architecture}

Michał Dzięcielski (Adam Mickiewicz University in Poznań, Poland), Maciej Kamiński, Maciej Szarejko (Urban Cybernetics Centre, Wrocław University of Technology, Poland), and Sara Zielińska (Adam Mickiewicz University in Poznań, Poland) presented a concept of Enterprise Resource Planning (ERP) tool, that would enable lean management to manage a city, but also provide for a participatory element. To manage a city in a democratic society, one cannot exercise an autocratic form of government, but also one cannot give a complete freedom either, as this would lead to an anarchy in a city, hence the need for a golden middle. M. Dzięcielski posited that ERP, originally conceived for big companies, can be adopted to give public participation a role in finding solutions that lead to improving the quality of life. The idea of an ERP for a city involves the ability to improve city foresight and allow the citizens to propose their ideas and in turn learn from experts

Table 1. The complementary case study approach involves three case studies in Dublin, Nottingham, and London (by A. Corcoran and Z. Nedovic-Budic).

\begin{tabular}{|c|c|c|c|}
\hline Case study elements & Research step & Common methodology & Analysis method \\
\hline \multicolumn{4}{|l|}{ Stakeholder group } \\
\hline Resilience principle & $\begin{array}{l}\text { Pre-design data } \\
\text { collection }\end{array}$ & Focus groups & Content analyses \\
\hline Resilience issue & $\begin{array}{l}\text { Pre-design data } \\
\text { collection }\end{array}$ & Focus groups & Content analyses \\
\hline \multirow[t]{6}{*}{$\begin{array}{l}\text { G-ICT (geographical information } \\
\text { and communication technology) }\end{array}$} & $\begin{array}{l}\text { Pre-design data } \\
\text { collection }\end{array}$ & Focus groups & Content analyses \\
\hline & $\begin{array}{l}\text { Prototyping devel- } \\
\text { opment }\end{array}$ & Programming & \\
\hline & Implementation & $\begin{array}{l}\text { Recruitment of prototype users/ } \\
\text { gathering of content }\end{array}$ & \\
\hline & \multirow[t]{3}{*}{ Evaluation } & Controlled experiment & Statistical analysis \\
\hline & & Focus Groups & Content analyses \\
\hline & & Survey & Statistical analysis \\
\hline
\end{tabular}




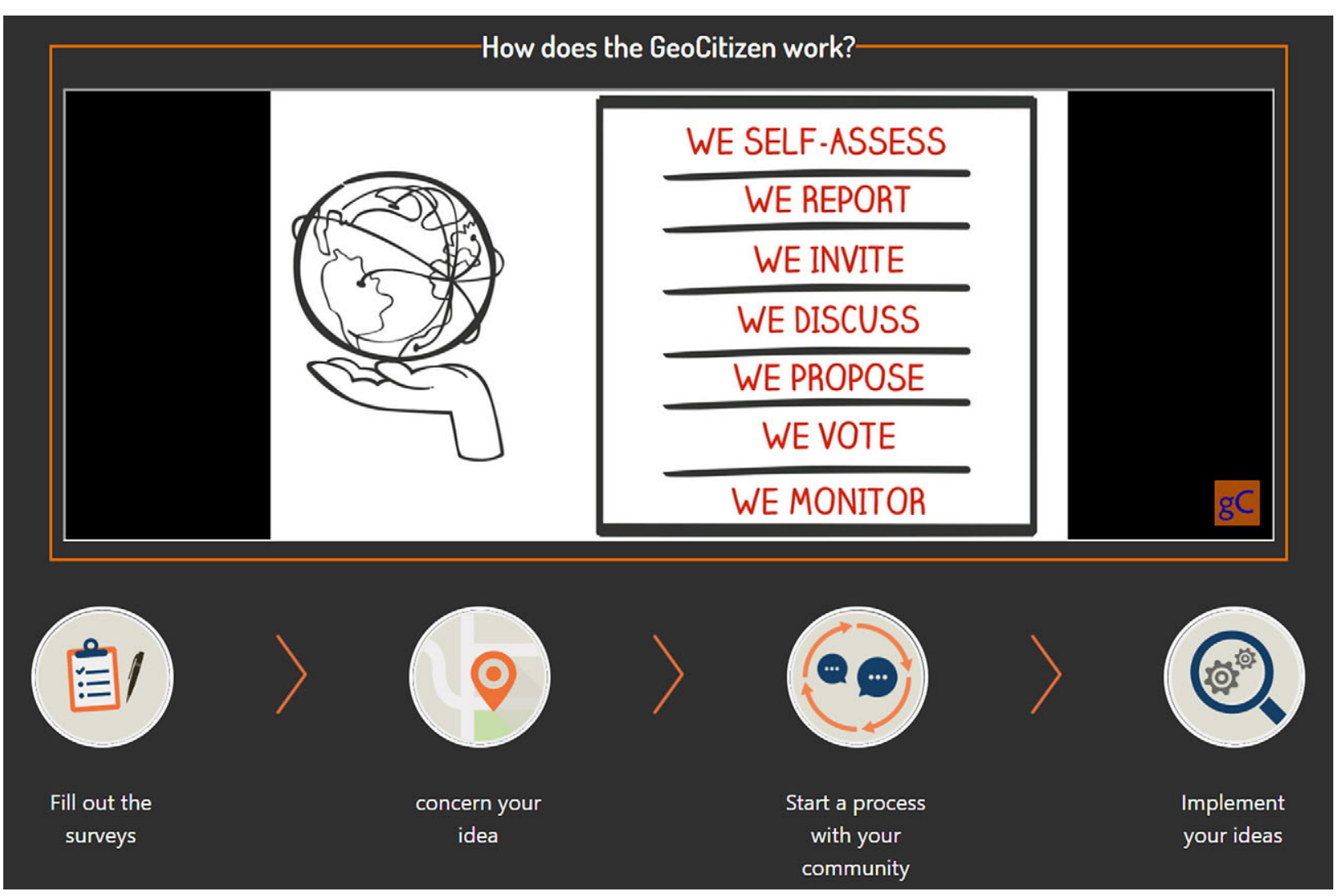

Fig. 3. Workflow for the GeoCitizen Platform (by Fundación CEC and Z-GIS Salzburg).

how they might impact the city. The concept also involves adopting ideas from lean management - ensuring that we give citizens the information that will support their needs, and from participatory budgeting, to allow people to create and fund their projects. According to the ERP concept for a city, people submit their ideas to the participatory projects support office (PPSO) in the city. The PPSO can explore, by using an ERP, which projects would result in unwanted outcomes and detract from the quality of life, and which project would benefit the quality of life. Using ERP and lean management, the project support office can help in selecting citizen ideas that are beneficial for the quality of life in the city.

\section{The GeoCitizen participation framework}

Thomas Blaschke and Karl Atzmanstorfer (University of Salzburg, Austria) presented the GeoCitizen Platform ${ }^{4}$ - based on 20 years

geocitizen.org of work that was done in the Department of Geoinformatics at University of Salzburg. The platform offers tools for transparent participatory community management with a structured process for communication between all stakeholders and assisting decision making processes. The functions include smartphone interface, web platform, and a management dashboard. The methodology involves browsing, collecting geographical information, sharing ideas which are geotagged, then discussing spatial content, rating proposals, and monitoring implementation (Fig. 3). The platform has been used, among others, in the town of Michaelnbach in Upper Austria, the Ecuadorian Amazon, San Vicente in Colombia, and in Barrio Bonito (south of Quito) in Colombia. The platform design allows to monitor, the process progress (Fig. 4) and promotes the inclusion of as many stakeholders as relevant to the process.

\section{Geo-discussion}

Dariusz Walczak (Recoded, Poznań, Poland) and Marek Młodkowski (Adam Mickiewicz 


\section{Lessons Learnt: Organizational Design $\quad$ GEOCITIZEN}

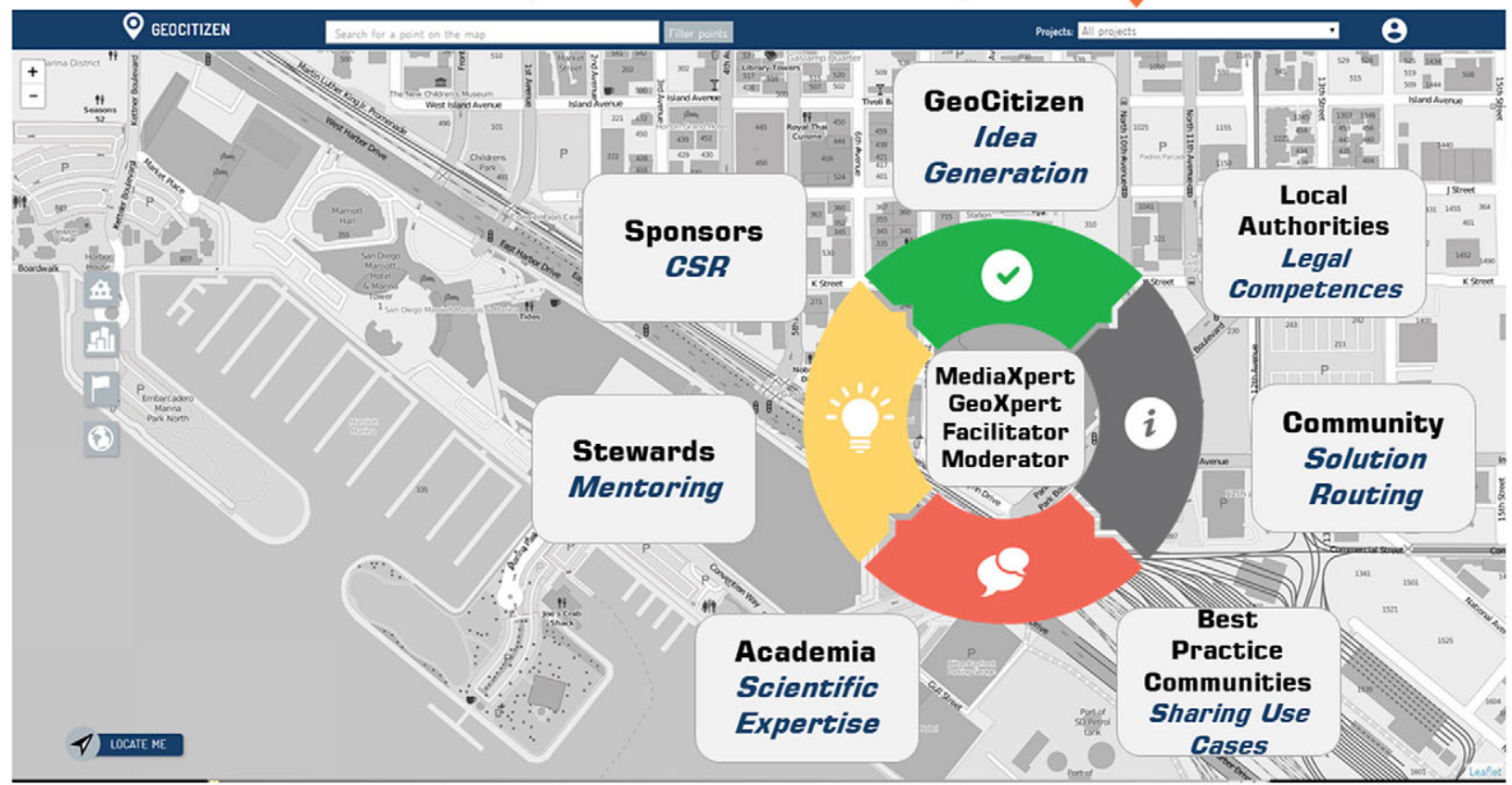

Fig. 4. Organisational design of the GeoCitizen Platform (by T. Blaschke and K. Atzmanstorfer).

University in Poznań, Poland) presented an application of geo-discussion method and tool as a result of the project ${ }^{5}$ about supporting public participation in urban planning through GIS (Bąkowska et al. 2016, Czepkiewicz et al. 2016, Jankowski et al. 2016, 2017 a, b, 2018). They demonstrated a case study in a suburban village of Rokietnica near Poznań (Fig. 5) involving a discussion about a local urban development plan. The geo-discussion could be accessed through a web browser on a laptop and on a mobile phone. The geo-discussion attracted 65 active participants ( $52 \%$ of returning participants to discussion) resulting in 131 discussion threads and 575 likes and dislikes to discussion threads. The participants were mostly younger; $51 \%$ of participants came from the age group 25-34. The Google analytics data revealed that the participants mostly used the desktop version of geo-discussion application. Each thread of the discussion had a unique URL and could be used to direct someone to a specific comment, see how many participants responded to a particular comment, when, and what they wrote. The administrator

Geoportal supporting public participation in spatial planning financed by the National Research and Development Center (contract number PBS3/A9/39/2015). of geo-discussion can see the threads and content of comments and can also hide some (e.g., offensive) comments. The process of setting up the geo-discussion tool for a specific application is simple and reduced to responding to short prompts that can open specific functions facilitating a discussion such as map and text interface. The system design includes many considerations on how to address the specific aspects of discussions in a way that produces actionable information for planners.

\section{Geodesign}

Michele Campagna and Chiara Cocco (University of Cagliari, Italy) showed their Geodesign framework application from the city of Cagliari in Sardinia. The origins of Geodesign framework lie in the work of Carl Steinitz from Harvard University and Hrishikesh Ballal from the Centre for Advanced Spatial Analysis (CASA) at University College London. There are many planning styles with different outcomes and methodologies. In the plan design process there is a need for planners and participants from the public to come together and deal with information, hence there is a need for simple interfaces. The Geodesign 

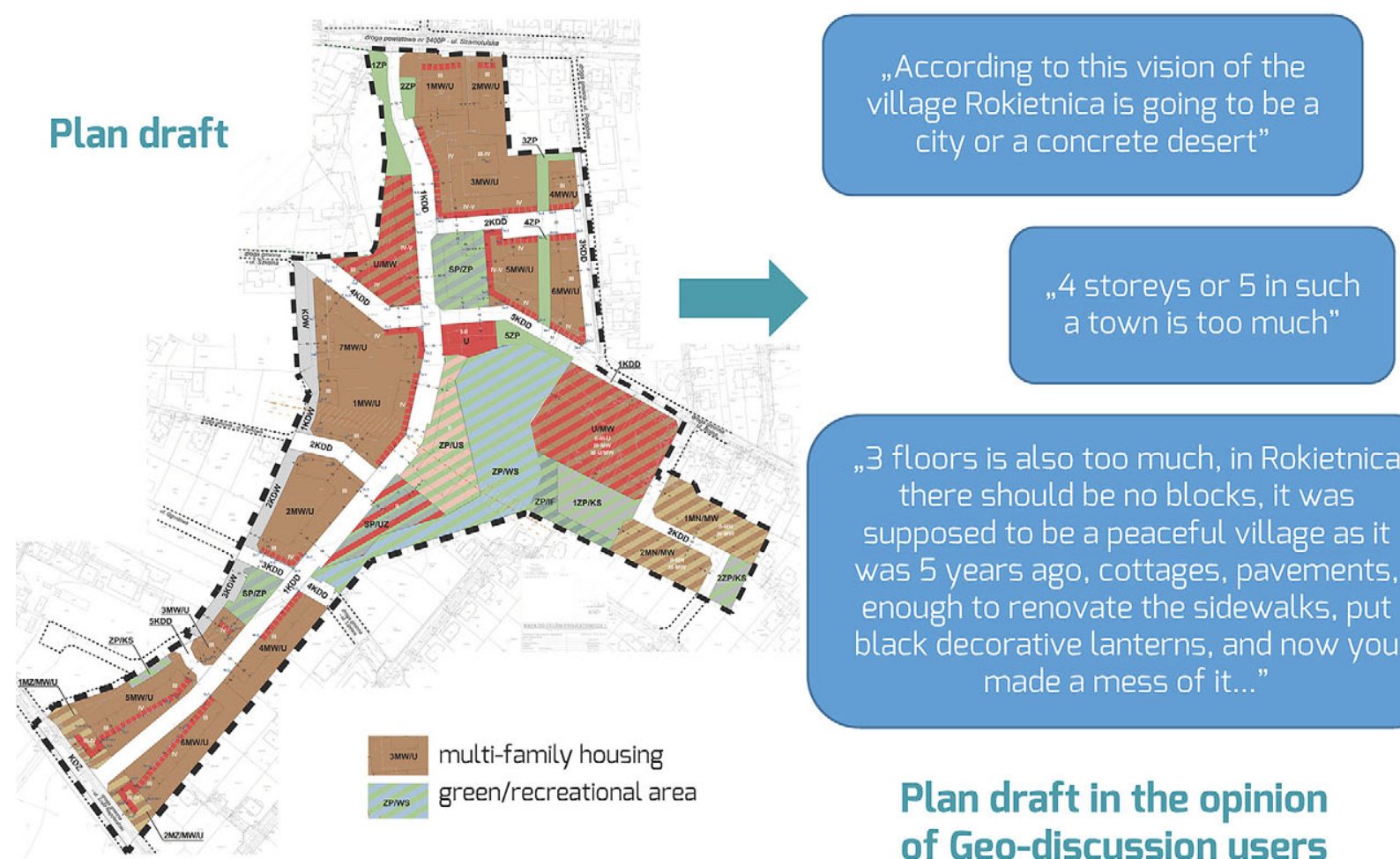

„3 floors is also too much, in Rokietnica there should be no blocks, it was supposed to be a peaceful village as it was 5 years ago, cottages, pavements. enough to renovate the sidewalks, put black decorative lanterns, and now you made a mess of it...

Fig. 5. Comments on draft plan of land use of the Rokietnica centre (by D. Walczak and M. Młodkowski).

framework is the core of Steinitz's model of Geodesign (Steinitz 2012). The framework starts with representation models and process models, and then moves on to employ evaluation models. There is a cycle of data-information-knowledge in the assessment phase and the intervention stage - the stages comprising Geodesign workflow. Geodesign $\mathrm{Hub}^{6}$ is a web application that supports Geodesign participatory process. The application is easy to use by lay participants and enables to quickly produce suitability maps that are coloured in a consistent way and the input data can be entered either by experts and/or by lay participants. New ideas involving changes to the existing land configuration can be sketched on diagrams in the form of simplified land use maps. People can copy diagrams contributed by other participants and adjust them. Diagrams can be created by experts and by lay participants. The participants can mark the diagrams that they especially like. Then it is possible to create a synthesis. The participants can also check and see the cost impacts of different land use changes. The hub is supporting the process of calculating costs, comparing options and assessing impacts.

$6 \quad$ www.geodesignhub.com

\section{A big data dashboard architecture for computable intelligent city policy}

Peter Nijkamp (Vrije Universiteit Amsterdam, Netherlands; Adam Mickiewicz University in Poznań, Poland) (in collaboration with Karima Kourtit) noted that the way we talk about policy needs to differentiate between goals and implementations. From an early stage in his studies, he learned that when people come with ideas, there can be a whole list of goals for policy, and the task of the scientists is to consider how to implement it. In a linear system, the number of goals will be exactly the number of instruments which is an assumption of how to implement policy. In the Netherlands, a consultation about sustainable development led to over 65 goals but without any thought of implementation, and therefore the plan failed. Dreams have to be confronted with reality - the human capabilities to look at the multiplicity of goals is limited (e.g. the magical number of 7) - beyond 7 it is not possible to achieve goals. In a scientific system, you need to minimise things to lead to very few critical factors. Simon (1976) published a paper about the economics of complexity over 30 years ago, in which he used the example of two watch repair 


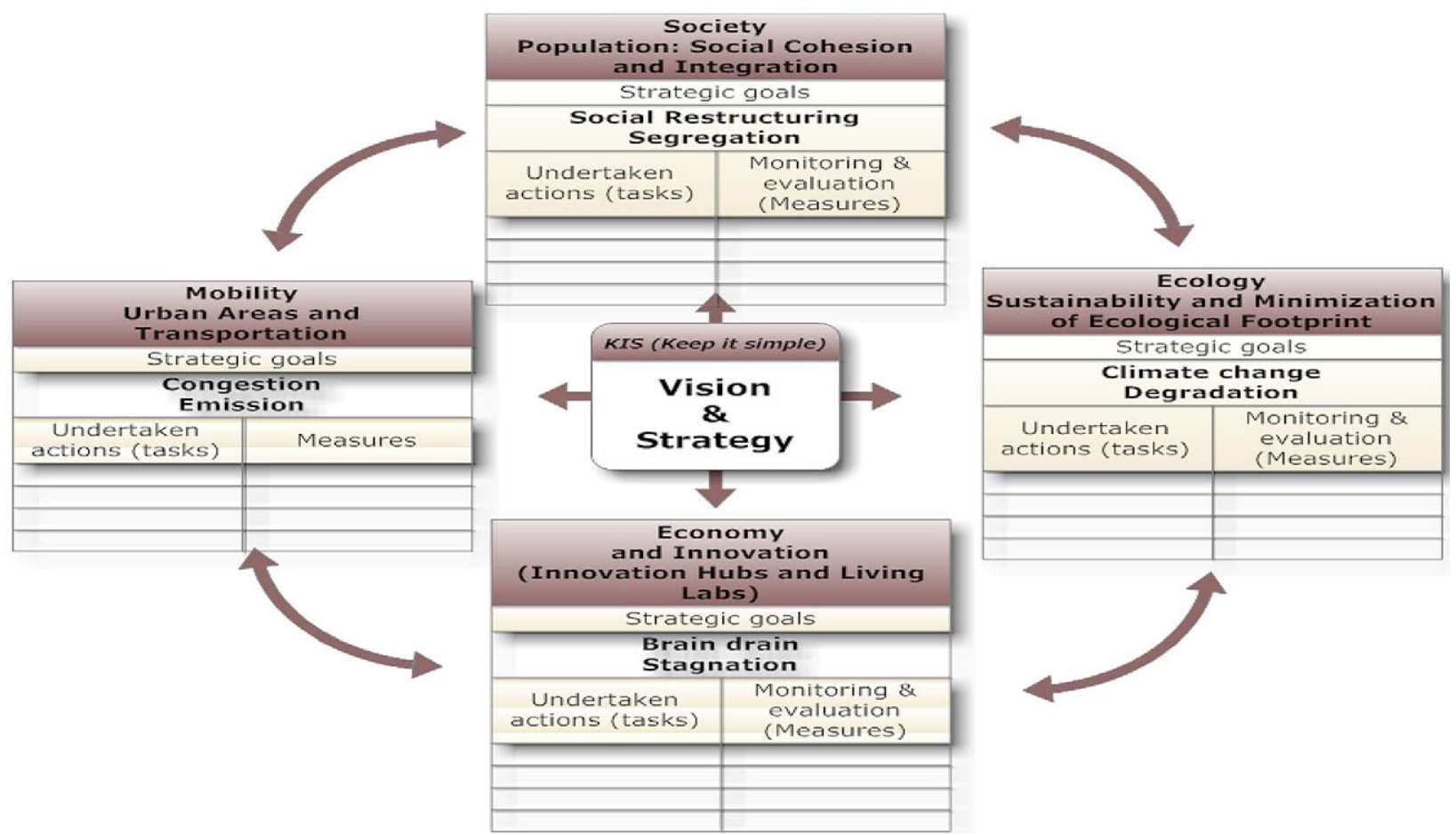

Fig. 6. P. Nijkmap's view on a smart, interactive navigation tool based on a balanced trade-off of Society, Environment and Economy.

people with one looking at all the details of the system and therefore ultimately failing, and the other who decomposes the system to sub-systems and that way manages to complete the task in a more efficient way. The number of aspects in a planning system is limited, and there can be a highly complex system that needs to be decomposed to few core sub-systems (e.g. car dashboard as a demonstration). The view that Simon is offering is a new urban world, in which we need to notice all the challenges in an urban environment - connected city, climate adaptation etc.

There have been many discussions about smart cities over the past decade. We need to think what we mean by that - the European focus has been on resources and the quality of life. The core element of any discussion on the idea of smart city is about the use of information and communication technology (ICT). The literature on the subject mixes the input side with the output side. Smart Cities require decomposition - economy, people, governance, mobility etc. Naturally, there are different rankings for quality of life, green city, etc., - there are all sorts of indicators but these are not very helpful. Global City Power Index, developed in Japan, is probably the best example. As the discussion about the smart city evolved, the Big Data challenges have appeared and the importance of the question of how to organise and manage them has increased. Batty (2013) pointed out that a city is not just a source of planning and activities, but also data. Are we going to find patterns in the data, or are we aiming to have a theory first? P. Nijkamp moved from just looking at the data, back to examining the theory and posited that we need an evidence-based approach. Thinking from the position of theory about rational planning, one has to consider first the mission of planning, and then take that into consideration methodological and operational aspects. The methodology involves things like information cascade or hierarchical filters. The operational side is computable and numerical. A dashboard, which exemplifies the operational side of planning, is a health check for a city or a region. The dashboard is an advisory and not a command and control system. The operational part of the city of Amsterdam involves looking at job creation, regional and international export position, innovation and entrepreneurship, and geographic concentration. The idea is to compare Amsterdam to other cities in space (spatial indicators) and across time. In urban systems, there are sub-systems and sub-sub-systems - focusing on each goal, but there is also an overall goal. The outcomes of the dashboard need to 
be interpreted within the wider ecological, social, and economic perspectives of the city (Fig. 6) - this requires an expertise in interpretation. Smart City is not only about the digital power since putting it in the hand of untrained end users will lead to a disaster. The system is assuming a stability in the planning of the goals and having long-term goals.

\section{Mapping web-application for digital participation in urban planning}

Jiří Pánek (Palacký University Olomouc, Czech Republic) demonstrated a system that is being developed in Olomouc in the Czech Republic and allows a subjective layer of emotional mapping of the city on top of thematic mapping. He uses the concept from Perkins (2009) about the emotional understanding of space and place. He also borrows the idea from Griffin and McQuoid (2012) about noticing maps of emotions, maps to collect emotional data, and finally emotions about using maps. Another consideration involves biometric measurements - e.g. BioMapping (Bergner et al. 2011), extraction of user-generated content but also surveys. While it is useful to understand that emotional maps can be relevant, he is also suggesting the concept of GeoParticipation ${ }^{7}$ (Pánek et al. 2014). This can be seen as an element of PPGIS, but it is also part of Participatory Planning Support System (PPSS). The approach depends on crowdsourcing, and has been deployed across the Czech Republic through a network of small towns promoting sustainability and working with over 40 cities. J. Pánek covered in his talk the concept of learning from failure. Using an analogue approach (just papers and pen) did work in terms of expressiveness but it was difficult to map it with pencil only. Also going only digital, with just allowing people to draw point, line, or polygon was not satisfactory either. This let J. Pánek to try to use only points, because heatmaps can produce wrong information about the city. He decided to collect points that are associated with a person, his/her background and interest. He combined paper and digital maps, and for the paper maps he used pins. This approach allowed to record details about who collected the

www.pocitovemapy.cz

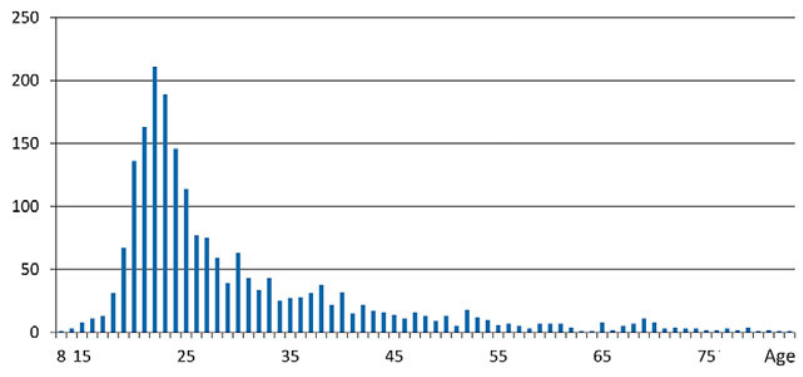

Fig. 7. Age distribution of respondents in Olomouc (by J. Pánek).

information and also to record participant demographic data. In Olomouc public participation application, there were 2,117 respondents - with 481 using paper mapping interface and 1,636 accessing web interface. The questionnaire focused on 6 spatial questions (In what public space do you feel well? Where are public spaces that are unattractive/ugly and should be improved? Where do you feel unsafe? Which areas could be improved regarding public transport? Which areas could be improved regarding walkability? Which areas should be developed in the future?) The respondents contributed 25,760 points/lines/polygons with 4,801 comments. The age distribution of participants was heavily skewed towards the younger age groups (Fig. 7), with half of participants who were university students and $45 \%$ with a university degree. The results allowed to identify 5-10 hot-spots to analyse further: the city needed simplified location data that they could use illuminated by participant comments. Some aspects of the analysis showed the focus of people on their local area, marking places where they felt happy and where improvements were needed. The lessons from this and other applications are fourfold. Points are sufficient for most of the case studies. Critical mass is really crucial - thousands of participants are important. Active engagement with local authorities is a must: without it there is no point in organizing participatory planning. Analysis of participant comments can result in further insights.

\section{Geo-questionnaire - a tool to support the process of social participation}

Bogna Kietlińska (University of Warsaw, Poland) is a sociologist and art historian who collaborates with geographers and cartographers. 
In her paper presentation, co-authored with Robert Olszewski and Agnieszka Turek (Warsaw University of Technology, Poland) she presented the results of geo-questionnaire answered by 154 respondents and concerning the public perception of a recently revitalized street (Tumska street) in the city of Płock. Płock is an old city, with the population of 126,000 and a university city with a lot of young people. The biggest problem on the Tumska street, which is the city promenade, is that there are many obstacles that make the street difficult to navigate. It is mostly shopping and services street and there are social problems: city-owned and rent-subsidized flats, homelessness, and the lack of trust in the city's intention to revitalize the area. In Poland many municipalities do not have spatial plans and there is little trust in the effectiveness of local governments. In the preparation for the geo-questionnaire project, B. Kietlińska and her co-authors looked at open geoinformation, volunteered geography information (VGI), spatial data mining, text mining and engaged multidisciplinary concepts cutting through science, art, and business. The questionnaire has provided an opportunity for respondents, to geolocate their answers making them less abstract and more suitable for participation in spatial planning (open geoinformation society). People could

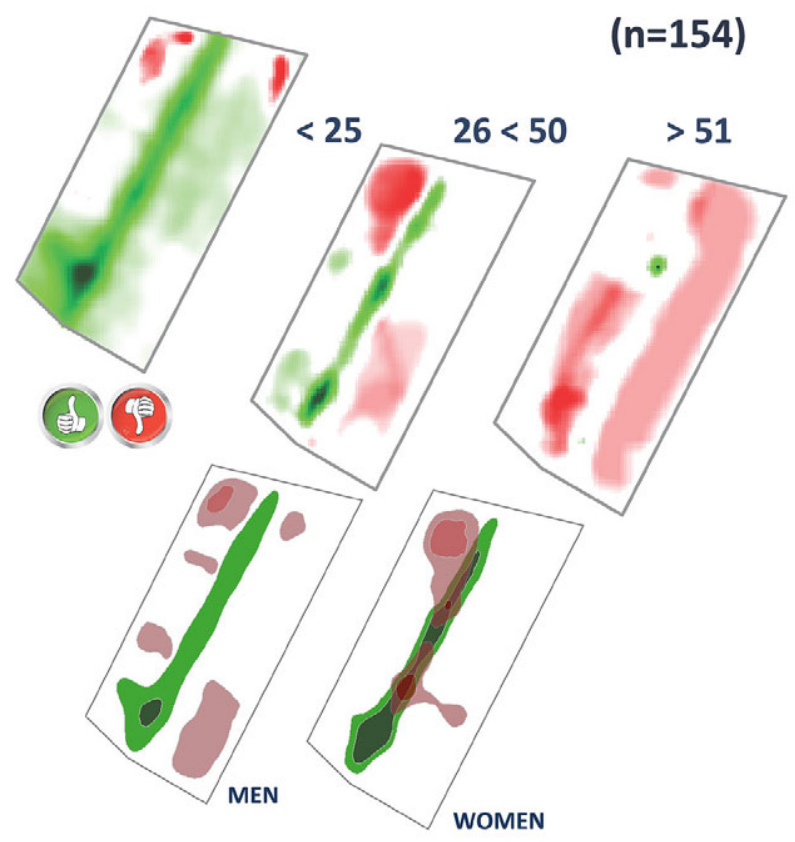

Fig. 8. Age and gender structure of respondents in geo-questionnaire on Tumska Street in Płock (by B. Kietlińska et al.). mark things that they liked and disliked and also respond to open questions. Respondents younger than 25 liked the street, respondents between 25-50 years had mixed opinion, and older people ( $>51)$ did not like the changes at all (Fig. $8)$. The limitations of the questionnaire are the issue of internet access and web use skills highlighting the issue of representativeness. There is also an issue of not considering human body in space. This perspective on who participates and in what way, draws from the phenomenology of perception, urban sociology and sensuous geography supported by thematic cartography. Hence, there is a need to contextualize the embodiment of experience and meaning in the realities of urban space. Emplacement creates certain association and understanding. One can think of ethnographic methods (walks, observations, collecting oral histories, etc.), design thinking with prototyping, and gamification (virtual and augmented reality, storytelling) as ways of capturing human experiences contextualized by urban spaces. Of particular interest to B. Kietlińska and her colleagues is gamification that offers possibilities of widening participation and deepening participant involvement. Another interesting method is an agent-based model of a city. Agentbased simulation models combined with a gamification approach can open new possibilities at addressing important questions about cities and engaging city residents at a deeper, more sustainable, and meaningful level.

\section{The Geo-Citizen participation framework: 15 years research, 3 years implementation - now serving societies worldwide}

Thomas Blaschke and Karl Atzmanstorfer (University of Salzburg, Austria) reported on the GeoCitizen framework, which is now well established and has been applied as a commercial service in selected countries of South America, Africa, and in Europe, particularly in small towns. The framework has also been applied to projects focused on assessing quality of life and well-being, relative to personal expectations and experiences, and carried out in collaborating with environmental psychologist. 
K. Atzmanstorfer reported on his work that is linked to Domingo Anjuasg of the Shuar Nation from the Ecuadorian Amazon, and received an award in the Amazon GIS initiative that was noted in 2016 ESRI user international conference in San Diego. The work on the project was is done with Richard Resl (GEOcentro UNIGIS, Universidad San Francisco de Quito). The technology of GIS has been used to "level the playing field" and aid the native people in the competition with corporations over the right to use natural resources in an area. Richard was asked, 25 years ago, to teach the Shuar on how to create maps. Domingo and the Shuar also wanted to communicate their life plans to the world. The pilot project of the GeoCitizen was to allow the Shuar people to discuss how they wanted to use their territory and how it should be used by people. This led to other cases in a more urban environment such as participatory infrastructure planning for Quito. That worked was followed by usability studies with marginalised communities in Cali, Colombia, working with black communities, people with little or no formal education, and asking them to carry out some tasks. Mapping tasks turned out to be difficult but other reporting tasks familiar from the use of social media turned out to be easy. One conclusion from these projects is that spatial literacy is a major obstacle. K. Atzmanstorfer and his colleagues are also considering serious games as a way to help people understand spatial information. An anecdote from their experience is that when GeoCitizen researchers carried out their work in the indigenous community, people who were aiming to rob them of their tablets turned into respondents once they understood what these tools were for. Interestingly enough, they brought the methodology honed during applications in South America back to Austria and have been using it in small villages in Austria. The basic concept is from local to multiple case studies. There is also an organisational design (see Fig. 4) that emphasizes having a local leader and facilitators. Applications of GeoCitizen framework require multiple skills: facilitators, people who are helping in understanding the GIS data, those who have skills in working with social media, and those who can train participants and keep them motivated. The lessons from the framework applications are: consider the neighbourhood scale, focus on ideas instead of complaints, keep the tool simple but structured, use local knowledge.

\section{Interoperability and visualisation as a support for mental maps to face differences in scale in Brazilian Geodesign processes}

Ana Clara Moura (Federal University of Minas Gerais, Belo Horizonte, Brazil), Tiago Marino (Federal Rural University of Rio de Janeiro, Brazil), Hrishikesh Ballal (Geodesign Hub Pvt Ltd, Ireland), Suellen Ribeiro (Federal University of Minas Gerais, Belo Horizonte, Brazil) and Silvio Motta (Pontifical Catholic University of Minas Gerais, Belo Horizonte, Brazil) co-authored a paper on Geodesign in Pampulha, Brazil. They used the framework of Geodesign (Fig. 9) proposed by Steinitz (2012). They followed the process through different models and iterated through the process 3 times - first finding the basic information and running the model twice to ensure that it was done correctly. They started with representation models in the first iteration. Significant work was required to create data for various landscape variables, such as vegetation. They classified maps to represent vulnerability and attractiveness and included in the process stakeholders representing developers, business, and environmental NGOs. The first iteration did not yield useful results. In the second iteration, an advertisement on YouTube was dedicated to recruiting relevant people with local knowledge. In the third iteration, A.C. Moura and her team used printed maps since just using computers alone was not working. As soon as the participants went to the computers, they left the paper, but this took 40 minutes of working with paper first. The process included a lot of talking about the participants discussing variables, maps, and process steps. In the end, the participants wanted just to consider three variables in modelling change to land use organization in Pampulha. The main contribution of the experiment was showing that the Geodesign workflow can be used to build different futures for the place, to arrive at more specific question that will be put out for a discussion, but also in educating people 


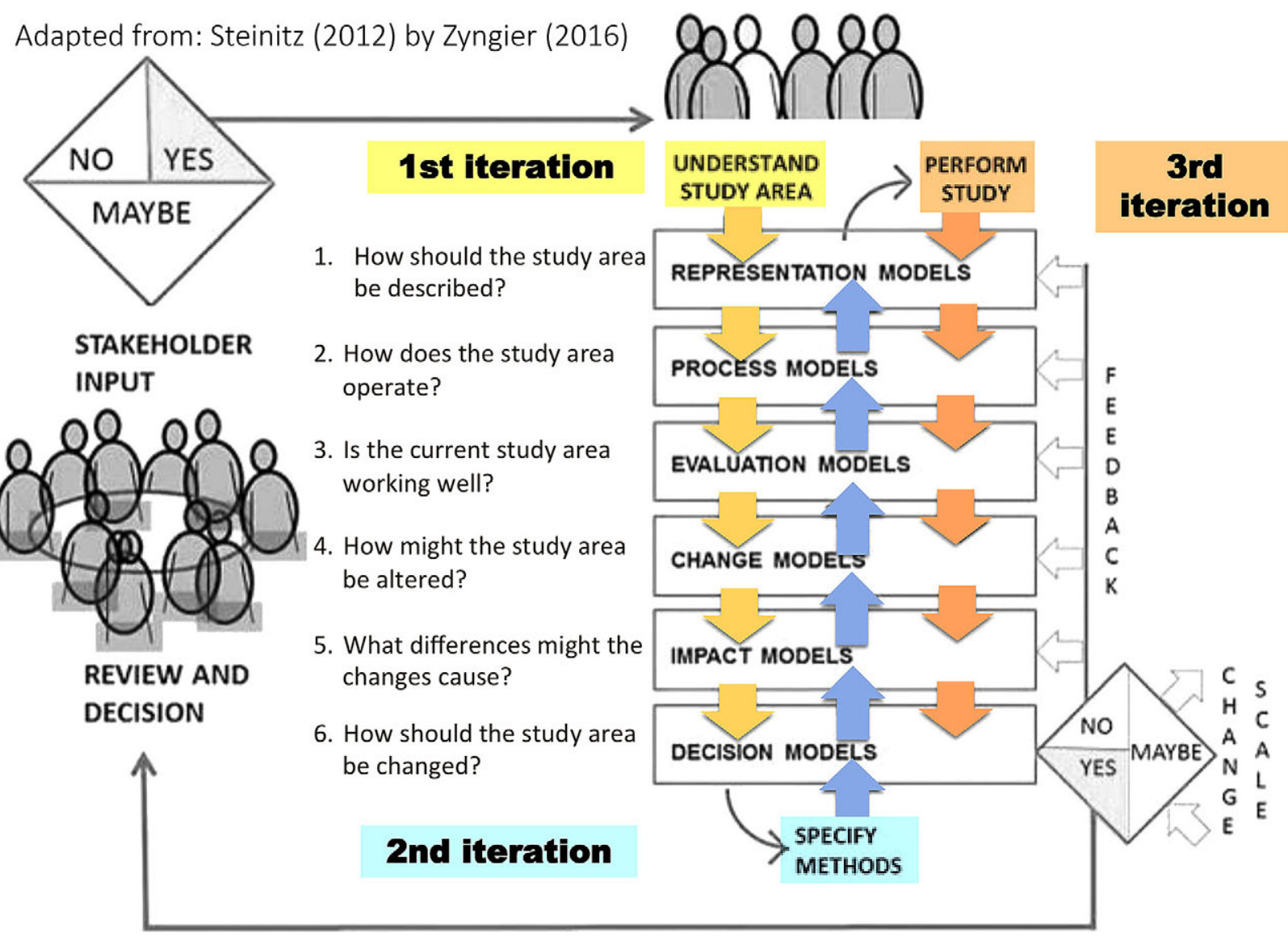

Fig. 9. Methodological framework of Geodesign for Pampulha in Brazil. The whole case study was developed in three iterations of Geodesign method (by A.C. Moura et al.).

about the implications of their choices. People who participated understood things that they did not understand before.

\section{Collaboration in planning: the Geodesign approach}

Michele Campagna and Chiara Cocco (University of Cagliari, Italy) presented software for a new planning support system. Following Arnstein's ladder (1969), other models of public participation in planning started to emerge specifically including information technology (Kingston 1998, Carver 2001). In particular Kingston's model (1998) focused participation on interests and agendas, and risk assessment in making a decision. In public participation we need to think about groups including participants, communities, and NGOs. In participatory planning the planner's role has changed from expert only to both expert and public participation coordinator.
The case they discussed was about running a Geodesign case of Cagliari metro area in Sardinia. The case involved a municipal plan and an attempt to collaborate with other nearby municipalities (17 of them), which did not have the culture of participation. M. Campagna and Ch. Cocco organized and led a Geodesign workshop over 2 days. The workshop goal was to create a land use change forecast for 20 years and consider 10 different urban systems. They started from an analysis of regulations and plans that allowed them to select those systems that would be the study focus. The systems were split into aspects in need of protection (e.g. ecology) and development (e.g. smart industries). The aspects were considered as system variables in estimating system impacts including the cost of change in the current land use configuration affecting urban systems. The workshop gave training to about 30 people from the university but also professionals from across the area - they played the roles of different stakeholders. The participants were asked to work as expert groups on each of 10 systems; each group 
was assigned to one system. Following the work on individual systems the participants created a map-based synthesis of proposed land use changes and measured some of the impacts of proposed changes. M. Campagna and Ch. Cocco also analysed the compatibility between groups and started negotiations and evaluating different models. They carried out two syntheses, the final discussion revealed some tensions, however, it ended with an agreed model. Planners, public administration, stakeholder and community members demonstrated that they were able to provide input in different stages of the process.

\section{Geodesign in Pampulha cultural and heritage urban area: visualization tools to orchestrate urban growth and dynamic transformations}

Ana Clara Moura, Camila M. Zyngier, Rogério Palhares and Flávio Carsalade (Federal University of Minas Gerais, Belo Horizonte, Brazil) presentation focused on a place in the state of Minas Gerais, Brazil where there is a historical place - cultural heritage in Quadrilatero Ferrifero. It is an important place with urban growth, mining, cultural heritage and the beginning of the Brazilian culture. They were influenced by Steinitz (2012) works. They created representation models and needed to produce data over two months. This would allow them to move to process models and evaluation model (Fig. 10). To represent the evaluation of existing land use structure on maps they used three levels of green for acceptable, yellow for not appropriate, and red for unacceptable. They have done that with the help of 10 researchers from the Federal University of Minas Gerais. For the Geodesign workshop they had 6 teams including people from communities, NGOs, who constituted groups that focused on change and conservation. The groups discussed different options for land use change, however, the participants were not linking the reality with the maps. It became evident that people did not understand where they situated the map diagrams and what was their meaning. To address that, A.C. Moura and her team realized that they needed to link the reality with digital representation and decided to use 3D visualisation relying on the work by Bishr (1998) that stressed the need for interoperability with other systems enabling the creation of different visualisations. Different forms of visualization allowed new ways of understanding the designs. By having a $3 \mathrm{D}$ representation people could use maps better and deal with scale problems. A.C. Moura and her co-authors concluded that the first iteration process presented a general alternative future scenario and the third iteration, that had a more specific set of key questions, achieved more detailed and accurate results. Geodesign is about alternative futures, and we need to share decisions and enable communication between people and between machines. We need to deal with reality, mental maps and digital representation.

\section{FirstLife - A geo-social network to support participation in urban design}

Alessia Calafiore and Lucia Lupi (University of Torino, Italy) present FirstLife ${ }^{8}$ - a geo-social network to support participation in urban design and city planning. It is about collecting georeferenced systems - places, groups, news and events and thinking about relationships among them on a temporal scale. The map allows filtering by time or by groups (Fig. 11). There are multiple points of view - a school can be viewed from a student, parent, teacher perspective. Although they have started with points of interest, A. Calafiore and L. Lupi are now dealing with building blocks of the base-map - such as selecting the whole building and trying to deal with the geometry according to the scale. The platform is addressing different aspects and objectives: from issues such as regeneration to new design. In that respect, they collect data to document projects and initiatives and to follow-up to ensure continuity. A. Calafiore and L. Lupi started the project with 6 municipalities, 30 schools, 60 teachers and 70 classes. The project started with planning activities, introduced the guidelines for mapping activities and moved to proposals about sites for regeneration. Workshops were carried out with different groups including students and teachers who had to be trained in the use of the platform. During the workshops the participants selected

\footnotetext{
firstlife.org
} 


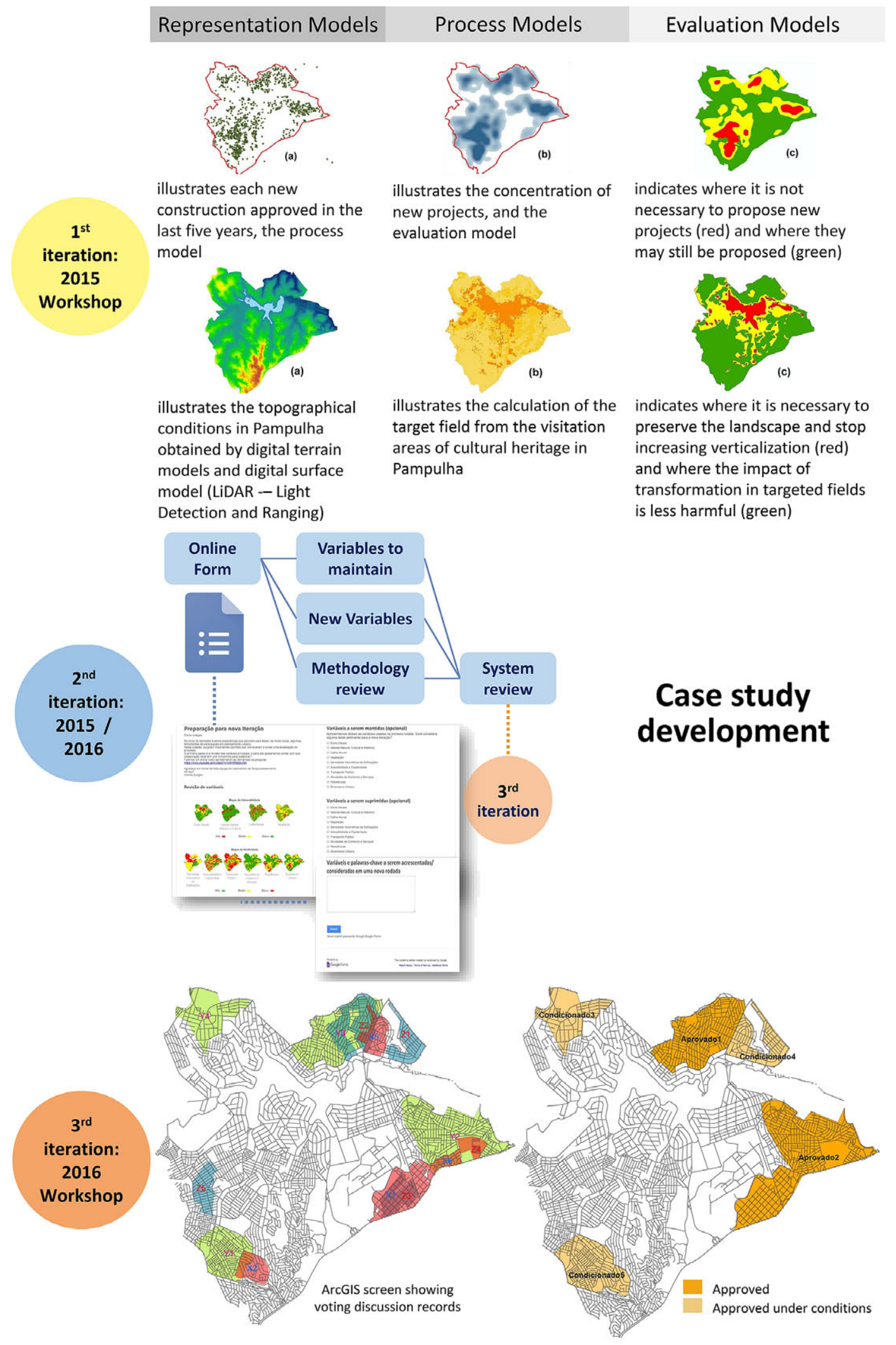

Fig. 10. The composition of three Geodesign iterations in the case study of Pampulha. Each iteration involves working with representation, process, and evaluation models resulting in the production of data, information, and knowledge, respectively. Following the account of the existing conditions, the proposal stage begins, which is related to change, impact and decision models that also produce data, information and knowledge, respectively (by A.C. Moura et al.). 


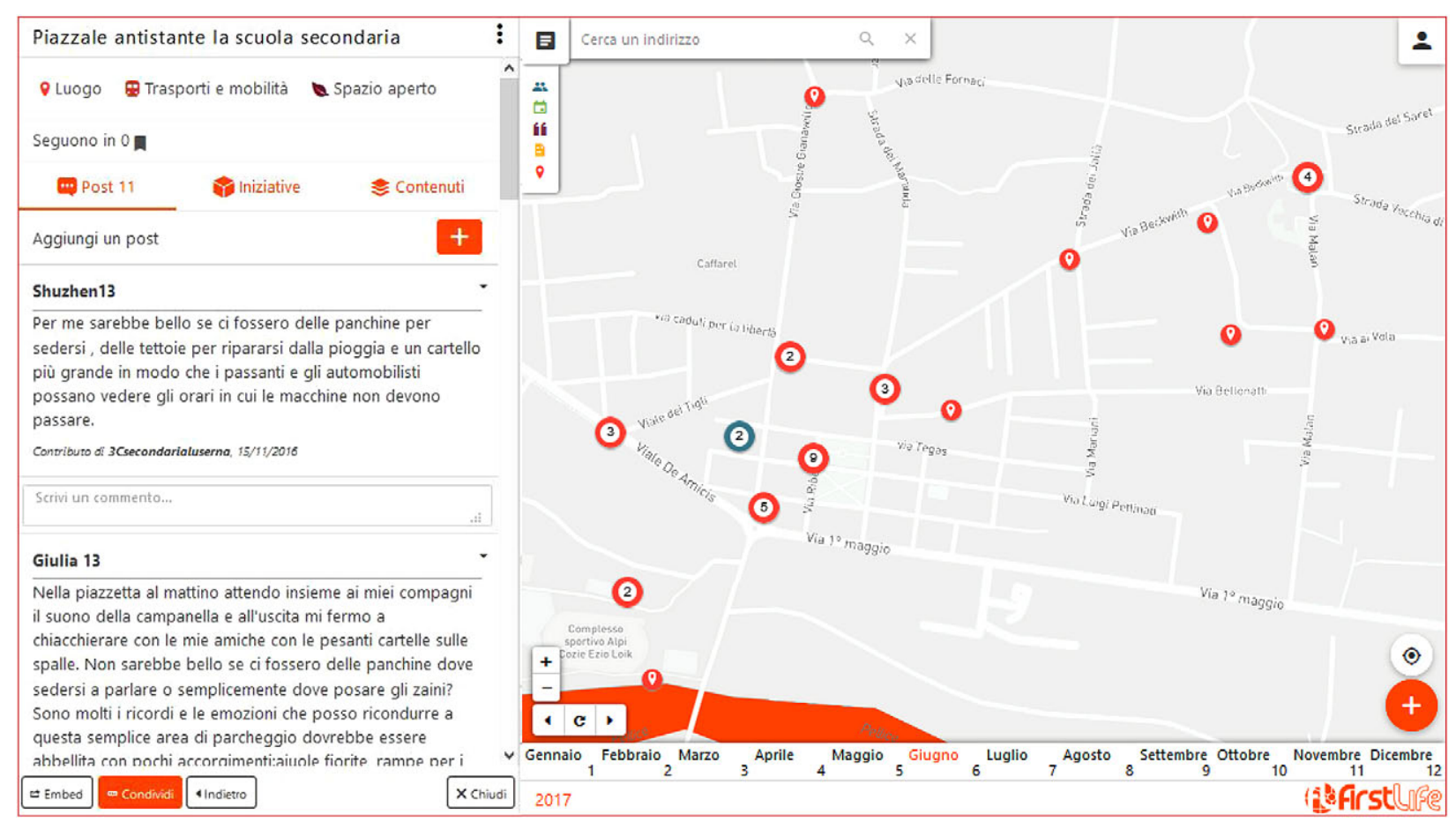

Fig. 11. Screenshot of Web-based application FirstLife (firstlife.org).

potential locations for regeneration. There were also focus group meetings to ensure that offline interactions were recorded and shared on the system. The follow up is to select proposals for recommendations on regeneration.

\section{Social participation in determining air quality in agglomerations}

Beata Jasiewicz, Jarosław Jasiewicz, Waldemar Ratajczak, Alfred Stach (Adam Mickiewicz University in Poznań, Poland) and Maciej Stroiński (Poznań Supercomputing and Networking Centre, Poland) discussed a collaboration between chemistry, geosciences and computer science. The discussed case, located in the City of Poznań, concerned urban air quality. Air quality is a growing problem in Poland, i.e.,. in Cracow, Poznan, Wrocław and other places. It is becoming an important political issue. There are also penalties for municipalities that are ignoring smog. There were 300 alarms of exceeding the limits of PM10,which is amongst the highest in Europe. There is a high concentration of PM10/ PM2.5 and $\mathrm{NO}_{2}$ across the city with 18 exceedances a year. The situation is slightly better on the side of $\mathrm{SO}_{2}$ There are many issues that affect the legal efficiency of addressing air quality at the regional level. There is a continued interest in air quality - in internet queries one can see many questions about $\mathrm{NO}_{x}$. However, some specialised terms are less searched online by the public: e.g., PM10 became a search term only in 2017, and other terms are not searched at all. Poznań has only 4 monitoring stations with only 2 running continuous monitoring - people want to see warnings being communicated to them. From the political point of view, the protection of the environment is centralised at the Ministry of Environmental Protection with state councils on nature conservation and another one on environment protection (experts in different areas). At the provincial level, the governor (Voivode) and the provincial inspector for environmental protection overlap with the oversight carried out by the national level authorities. At the provincial level, there are different mechanisms: public consultations, linking with NGOs, public independent initiatives, and of course citizen independent actions and protest, but also independent citizens budgets. At the city level there are the city council and the mayor who have environment protection responsibilities. The regional council also has environmental responsibilities funded by the provincial fund for environmental protection. Offering new ideas requires negotiating with lots of organisation. J. Jasiewicz and others tried to address 
Based on:

Act on Land Use Planning and Management of 27 March 2003

Statutory forms:

- public presentation of the plan

- public discussion

- formal motions for alteration of draft plan

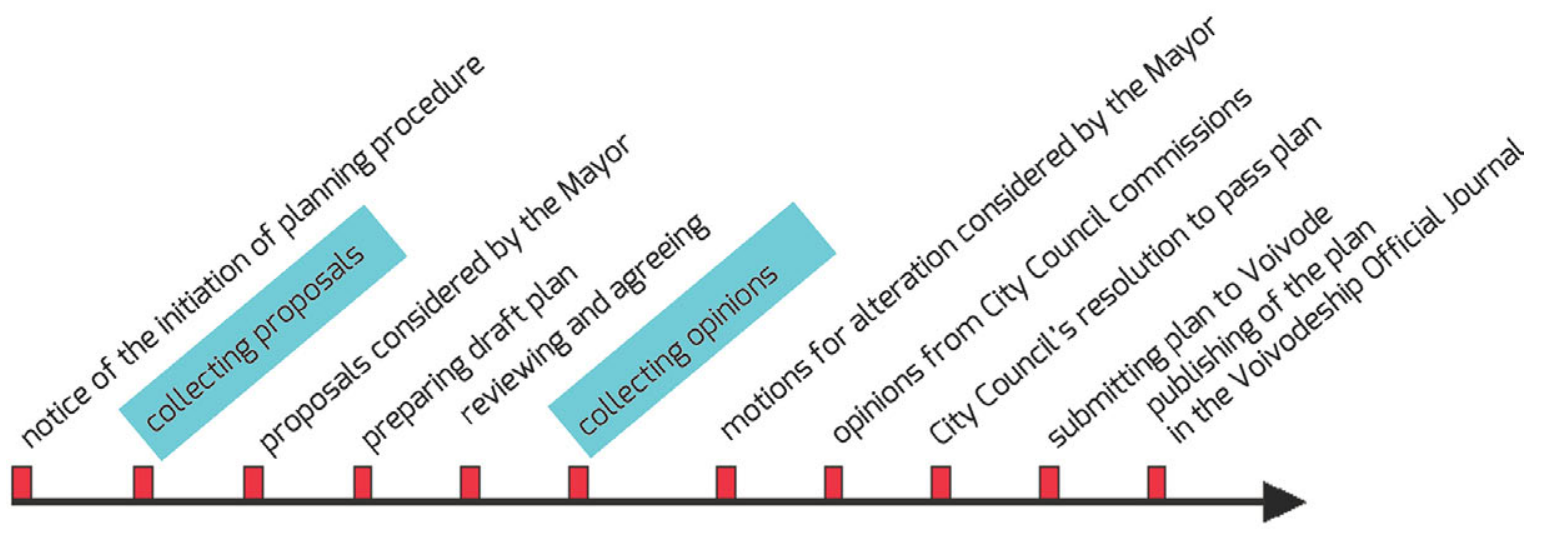

Collecting proposals

to the plan draft

Collecting opinions

$\&$ public discussion

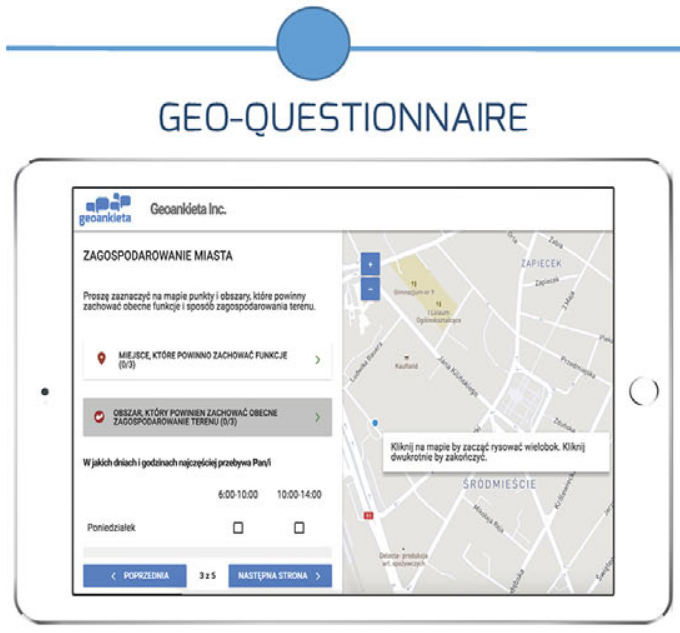

\section{GEO-DISCUSSION}

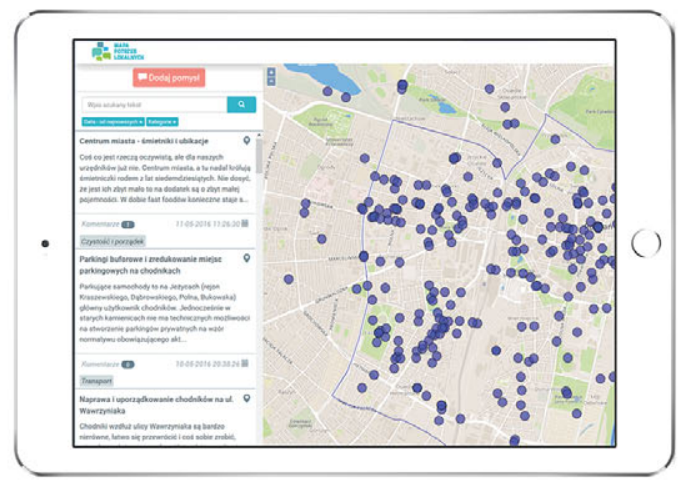

Fig. 12. Public participation in urban planning in Poland and Web-based applications of geo-questionnaire and geo-discussion (by E. Bąkowska et al.).

the problem of air pollution through Public Independent initiative at the city level - with the mayor and city council. To do that, they looked at the concept of smart and digital city and considered sensors of air quality. They also considered forecasting of the conditions through emission data, topographical data and weather data. They started doing simulations of pollutants dispersion in the city and also considered modelling air movement in the street. They are now considering applications and services that will help people plan where they should go for outdoor activities. They examined a similar system that involved communities in Krakow, Wrocław, and also looked at other systems.

\section{Applications of Geoweb Methods in Urban Planning on the Examples of Selected Polish Cities}

Edyta Bąkowska, Marek Młodkowski and Łukasz Mikuła (Adam Mickiewicz University in Poznań, Poland) presented a project aimed to support public participation in urban planning 9 . The authors noted the need for collecting spatial

9 Geoportal supporting public participation in spatial planning financed by the National Research and Development Center (contract number PBS3/A9/39/2015), geoplan.amu.edu.pl. 
planning proposal at the beginning of the planning process, and collecting opinions in the draft stage of the plan (Fig. 12). This includes a public presentation of the plan, public discussion, and formal motions for alterations.

The authors reported on developing a geo-questionnaire tool to collect proposals, and a geo-discussion tool to collect opinions and facilitate on-line public discussion (Bąkowska et al. 2016, Czepkiewicz et al. 2016, Jankowski et al. 2016, 2017 a, b , 2018). As part of applied research project, they have done 10 public consultation processes - 6 with geo-questionnaire, and 4 that included both tools. These projects attracted 7500 active participants and further 97 participants in 2 geo-discussions. The cases were located in the Poznań and Łódź agglomerations. The cases included land use plans, urban design and urban renewal, transportation plans, maps of local needs, and quality of life diagnosis. The case study areas ranged from 1 ha to 200,000 ha. In a sub-urban village of Rokietnica they had an interesting case - a fast growing area, doubling in population over 10 years. The case study focused on an abandoned 16 ha site located in the village

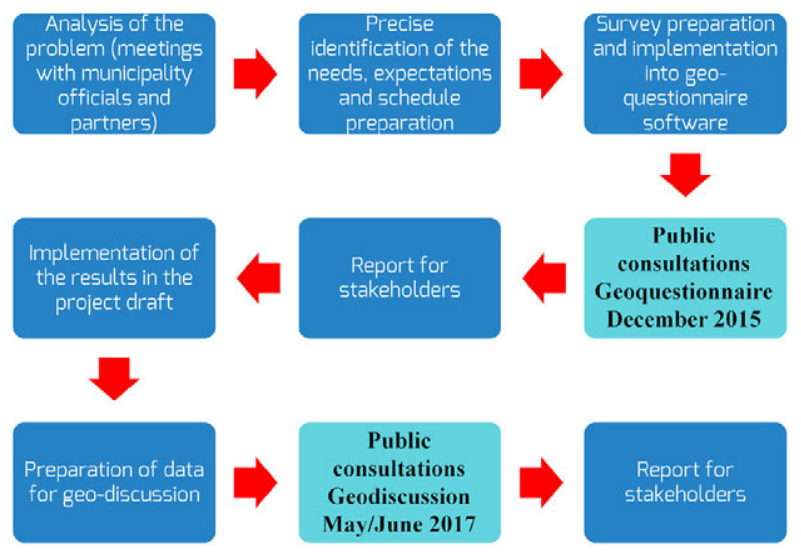

Fig. 13. Structured process of decision-making in urban planning (by E. Bąkowska et al.).

centre. The authors have used a structured participation process (Fig. 13) and carried out the questionnaire in December 2015 followed by the geo-discussion in May/June 2017. The process has been a long one, in terms of transferring landuse plan to the system. The geo-questionnaire had 435 respondents, about $3.3 \%$ of the resident in the village with over-representation in the 25-45 age group. In the geo-discussion, 65 people participated creating 131 discussion threads, with 51\%
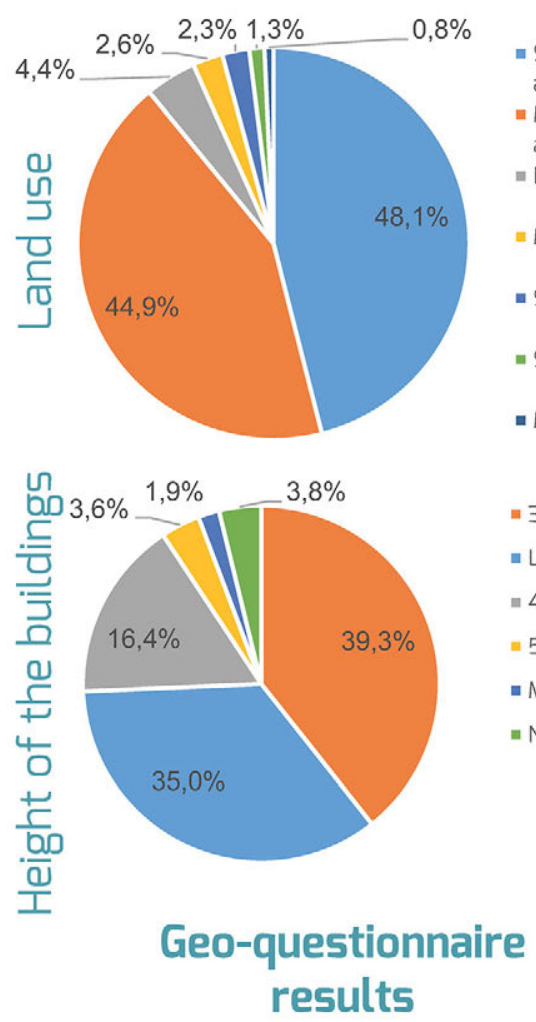

- Single-family housing with services and recreational areas - Multi-family housing with services and recreational areas = No opinion

" Multi-family housing with services - Single-family housing - Single-family housing with services - Multi-family housing - 3 floors - Less than 3 floors 4 floors 5 floors - More than 5 floors No opinion

Fig. 14. Some results of geo-questionnaire and their influence on the formation of draft land use plan (by E. Bąkowska et al.). 
Table 2. Proposed dimensions of PPGIS design (by M. Czepkiewicz et al.).

\begin{tabular}{|c|c|c|}
\hline $\begin{array}{l}\text { Socio-institutional context } \\
\text { of participation process }\end{array}$ & $\begin{array}{c}\text { Participants } \\
\text { Who is participating? }\end{array}$ & $\begin{array}{c}\text { Technology } \\
\text { Design considerations for PPGIS GIS } \\
\text { tools }\end{array}$ \\
\hline $\begin{array}{l}\text { Rules and norms } \\
\text { Planning approach } \\
\text { Situation in the planning process } \\
\text { Objectives } \\
\text { Conveners and recipients } \\
\text { Subject } \\
\text { Resources } \\
\text { System of tools and communication } \\
\text { channels }\end{array}$ & $\begin{array}{l}\text { Knowledge available to participants } \\
\text { Selection criteria } \\
\text { Group size } \\
\text { Recruitment }\end{array}$ & $\begin{array}{l}\text { Direction of communication } \\
\text { Type of interactions } \\
\text { between participants } \\
\text { Types of contributions } \\
\text { Input format } \\
\text { Geographic information aids }\end{array}$ \\
\hline
\end{tabular}

participants in the 25-34 age group. The result is that views from the geo-questionnaire have influenced the planning, but the planners decided to locate multi-family buildings in places where the participants suggested single family houses (Fig. 14). Strong opinions about the suggested density were expressed in the geo-discussion (Fig. 5). This case study obviated the need for legal regulations on the use of Geoweb tools such as geo-questionnaire and geo-discussion. It also showed the need for better integration of information obtained from participatory processes in planning practice.

\section{An Integrated Approach to Public Participation in Urban Planning with Geoweb Methods}

Michał Czepkiewicz (Adam Mickiewicz University in Poznań, Poland; University of Iceland, Reykjavik, Iceland), Piotr Jankowski (San Diego State University, San Diego, USA; Adam Mickiewicz University in Poznań, Poland) and Cezary Brudka (Poznań University of Economics, Poland) explored the ability to think about urban planning phases and supporting the designers in what they need to integrate the tools into the process of urban planning. They developed a diagram representing constructs, aspects, premises, and relations between the constructs comprising Enhanced Adaptive Structuration Theory 2 (EAST2) framework (Jankowski 2011). They see the socio-institutional context of the participatory process, considering the participants and the technology, as indispensable for design consideration. They proposed several dimensions (Table 2) using Kahila-Tani's (2016) ideas of moving towards more collaborative planning under the constraints of planner-centred process restricting public access to information. M. Czepkiewicz and his co-authors see the need to consider the diagnosis of current situation as the preliminary step for participatory planning. They identified the tools (Fig. 15) that can match knowledge and flow of knowledge between participants, e.g.,
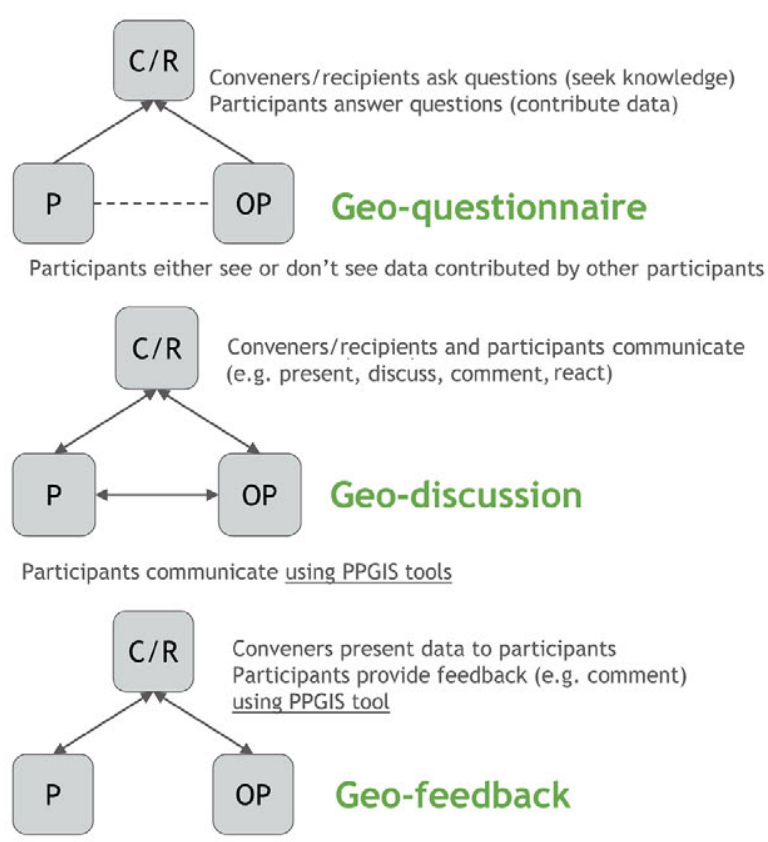

Participants do not communicate between themselves using PPGIS tools

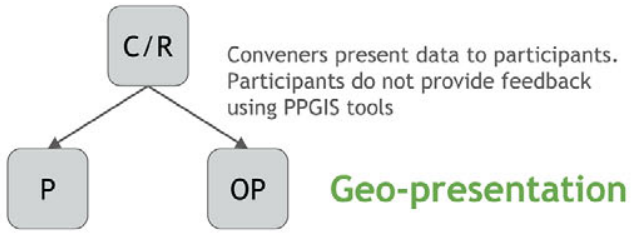

Participants neither communicate between themselves nor with conveners/recipients using PPGIS tools

$\mathrm{C} / \mathrm{R}$ - conveners/recipients, $\mathrm{P}$ - participants, $\mathrm{OP}$ - other participants

Fig. 15. Framework for an integrated approach to public participation in urban planning (by M. Czepkiewicz et al.). 
geo-questionnaire that provides information from participant to the convener, but does not support communication between participants. They also pay attention to the linkage and transfer of information and posit a question of whether is it just about informing or achieving shared understating? Geo-questionnaires provide one-way communication but do not support a two-way information sharing. This works in some public participation cases, but not in those that require moving away from rational planning practices towards communicative and evidence-based planning.

\section{Volunteered Geographic Information for planning: the case for "emergent" cycle lanes in cities}

Antonello Romano and Stefano Picascia (University of Siena, Italy) looked at ways of integrating VGI into the planning process. They were looking at VGI assuming wisdom of the crowds, and specifically focused on Strava data coming from bicycle users. The data are sold for profit $-\mathrm{a}$ wealth of data that can be useful. They explored the options of using this data to help with planning of cycle routes - identifying routes where a high number of trips are taken. Arguably the network of bike paths is emerging from multiple cyclists and there is an opportunity to find out why these routes emerge. To understand the data there is a need to use the infrastructure data such as bicycle path network combined with topography, information about incidents and accidents and other bits of information, in order to be able to explain the cycling pattern. Trips taken on the cycling network and those that are outside the network help to reveal the usability of the current cycling network including its bottlenecks such as roundabouts and places where the cycling network does not continue. Some observations from Rome do not match the data and there are questions if we should use Strava data. There are data problems including: data quality and accuracy, demographic profile, price, ethics. Elderly cyclists do not use mobile phone applications such as Strava. There is an issue of data that is valuable for the society, but due to its proprietary nature such data locked by the company and inaccessible to the public.

\section{Conclusions}

In summary, the meeting highlighted seven major points that can be relevant to the wider area of participatory approaches in geography that are utilising ICT.

First, understanding ICT use by people belonging to different groups - concern about digital exclusion and how different people have access and ability to use participatory systems. There is an increasing engagement with technology, but because of the persistence of the age distribution of those who participate we seem to have an issue with people at an older age, and therefore need to have strategies for inclusion. Another opinion pointed about collaboration between millennials and older people as one way to address this. That said, the ability of older groups to acquire information and learn is lower than that of younger people. This speaks to the need to consider how artificial intelligence (AI) assistance can be used to improve participation among older groups. We need to be aware of the ever-changing technology need to consider how it may be narrowed with future technology.

Second, we need to consider the experiences concerning to legal regulations in the context of participation: in urban planning, there are regulations in Italy that open the option but do not mandate it. One needs to be aware of implications for different bodies even within the same state. In Ireland, data protection and ownership are coming as a major concern for organisations about what is collected and where. In Brazil, there is a law that requires participation in planning, but what type of participation and which level of participation - it is not made explicit. In the USA, there is a federal system that allows independent bodies to collaborate - counties do have a lot of power, and cities do their own planning. Based on the ideas of federalism they do things their own way. Some cities are more participatory due to their culture, while other are not trying to engage people. Poland has experienced growth in soft informal planning - pre-planning processes that open opportunities for planning.

Third, we need to consider what are necessary conditions for cooperation between city planners and public participation representatives? In Italy it is impacted by the wider atmosphere, with planners being limited by the current politics 
and guidance. In the Polish system, the city planners are also limited within their focus and remit - they are not asked to do public participation. Other experiences in Poland point that planners have specific needs for information, which require following a top-down process to allow for public participation. There is a need for a process that allows for symmetric information exchange. In Brazil, the planners act as the designers of the city and they somewhat resist to be the decoder of collective values. There are also restrictions in terms of the role and what is expected from the private or the public planner. For example, if the private planner office does not want to expose the information to the public, the public planners are limited in what they can do. There are situations in which the public and private actors should work together to engage the public.

Fourth, while there is a growing popularity of new methods, there are differences in locations according to their legal and organisational structures.

Fifth, the role of social movements in shaping of liveability in cities needs to be taken into account. Social movements make problems visible and expose problems - but they then require the experts to be involved in setting it out. They have a role to highlight issue, and because planning and city management is longer time scale, the relationships are more complex.

Sixth, regarding new methods and tools that will be most useful: visualisation is important for communication. Techniques (e.g. Space Syntax) as well as old tools such as sketching and also existing methodologies need to be integrated. The importance of virtual and augmented reality was also raised. DIY science ${ }^{10}$ and data collection will come along, and in social science there are questions about using existing data sets and collaborating systems.

Finally, also the issues of linkage between information from participatory methods and tools and choices made by decision makers - and constraints on the use of information accessible and usable. Getting access to data is a problem inside organisations and sometimes there can be changing the way people structure processes. Also, wide scale political processes and general atmosphere signal to the public and the planners whether there is is more scope for participation and if the participatory effort will be treated seriously or not.

\section{Acknowledgments}

The review and discussion described in this paper were conducted as part of the project Geoportal supporting public participation in urban planning financed by the National Research and Development Center (contract number PBS3/ A9/39/2015).

\section{References}

Arnstein S.R., 1969. A Ladder Of Citizen Participation. Journal of the American Planning Association 35(4): 216-224.

Batty M., 2013. Big data, smart cities and city planning. Dialogues in Human Geography 3(3): 274-279.

Bąkowska E., Kaczmarek T., Jankowski P., Zwoliński Zb., Mikuła Ł., Czepkiewicz M., Brudka C., 2016. Geo-questionnaire in urban planning - preliminary results of the experimental application in Poland. Rozwój Regionalny $i$ Polityka Regionalna 35: 37-54.

Bergner B.S., Zeile P., Papastefanou G., Rech W., Streich B., 2011. Emotional barrier-GIS - a new approach to integrate barrier-free planning in urban planning processes. In: M. Schrenk, V.V. Popovich, P. Zeile (eds.), REAL CORP 2011. Changes for Stability - Lifecycles of Cities and Regions. The Role and Possibilities of Foresighted Planning in Tranformation Processes. Proceedings of 16th International Conference on Urban Planning, Regional Development and Information Society: 247-257.

Bishr Y., 1998. Overcoming the semantic and other barriers to GIS interoperability. International Journal of Geographical Information Science 12(4): 299-314.

Carver S., 2001. Participation and Geographical Information. ESF-NSF Workshop on Access to Geographic Information and Participatory Approaches Using Geographic Information, Spoleto, 6-8 December 2001.

Czepkiewicz M., Brudka C., Jankowski P., Kaczmarek P., Zwoliński Zb., Mikuła Ł., Bąkowska E., Młodkowski M., Wójcicki M., 2016. Public Participation GIS for sustainable urban mobility planning: methods, applications and challenges. Rozwój Regionalny i Polityka Regionalna 35: 9-35.

Dunn Ch.E, 2007. Participatory GIS - a people's GIS. Progess in Human Geography 31(5): 616-637.

Feenberg A., 1999. Questioning Technology. Routledge, New York.

Ghose R., 2001. Use of Information Technology for Community Empowerment: Transforming Geographic Information Systems into Community Information Systems. Transaction in GIS 5(2): 141-163.

Gottwald S., Laatikainen T.E., Kyttä M., 2016. Exploring the usability of PPGIS among older adults: challenges and opportunities. International Journal of Geographical Information Science 30(12): 2321-2338. 
Griffin A.L., McQuoid J., 2012. At the Intersection of Maps and Emotion: The Challenge of Spatially Representing Experience. Kartographische Nachrichten 62(6): 291-299.

Jankowski P., 2011. Designing Public Participation Geographic Information Systems. In: T.L. Nyerges, H. Couclelis, R. McMaster (eds.), The SAGE Handbook of GIS and Society. SAGE Publications, London: 347-360.

Jankowski P., Czepkiewicz M., Młodkowski M., Zwoliński Zb., Wójcicki M., 2017a. Evaluating the scalability of public participation in urban land use planning: A comparison of Geoweb methods with face-to-face meetings. Environment and Planning B: Urban Analytics and City Science. DOI: $10.1177 / 2399808317719709$.

Jankowski P., Kaczmarek T., Zwoliński Zb., Bakowska-Waldmann E., Brudka C., Czpkiewicz M., Mikuła Ł., Młodkowski M., 2018. Zastosowanie aplikacji geoankiety $i$ geodyskusji w partycypacyjnym planowaniu przestrzennym - dobre praktyki. Bogucki Wydawnictwo Naukowe, Poznań: 1-81.

Jankowski P., Kaczmarek T., Zwoliński Zb., Mikuła Ł., Wójcicki M., Bąkowska E., Czepkiewicz M., Młodkowski M., Brudka C., 2017b. Narzędzia internetowe w konsultacjach społecznych w planowaniu przestrzennym. Idea, obszary zastosowań $i$ wdrażanie. Wydawnictwo Naukowe UAM, Poznań: 1-58.

Jankowski, P., Czepkiewicz, M., Młodkowski, M., \& Zwoliński, Zb. (2016). Geo-questionnaire: A Method and Tool for Public Preference Elicitation in Land Use Planning Piotr. Transactions in GIS, 20(6), 903-924. DOI: 10.1111/tgis.12191.

Kahila-Tani M., 2016. Reshaping the planning process using local experiences: Utilising PPGIS in participatory urban planning. Aalto University publication series Doctoral Dissertations 223.

Kingston R., 1998. Web Based GIS for Public Participation Decision Making in the UK. Empowerment, Marginali- sation, and Public Participation GIS. National Centre for Geographic Information and Analysis, Santa Barbara, California, October 14-17th, 1998.

Kwan M.-P., 2008. From oral histories to visual narratives: re-presenting the post-September 11 experiences of the Muslim women in USA. Social \& Cultural Geography 9(6): 653-669.

Laituri M., 2003. The Issues of Access: An Assessmnet Guide for Evalualting Public Participation Geographic Information Science Case Studies. URISA Journal 15: 25-32.

Obermeyer N.J., 1998. PPGIS: The evolution of Public Participation GIS. Catography and Geographic Information Systems 25: 65-66.

Pánek J., Kubásek M., Valůch J., Hrubeš M., Zahumenská V., 2014. GeoParticipace: Jak používat prostorové nástroje $v$ rozhodování o lokalitách, ve kterých žijeme? Univerzita Palackého v Olomouci: 1-76.

Perkins C., 2009. Performative and Embodied Mapping. In: R. Kitchin, N. Thrift (eds.), International Encyclopaedia of Human Geography, Elsevier, London: 126-132.

Sieber R.E., 2004. Rewiring for a GIS/2. Cartographica 39(1): 25-39.

Simon H.A., 1976. From Substantive to Procedural Rationality. In: S. Latsis (ed.), Method and Appraisal in Economics, Cambridge University Press, Cambridge: 65-86.

Steinitz C. (ed.), 2012. A Framework for Geodesign: Changing Geography by Design. Redlands, CA: ESRI Press.

Talen E., 1999. Constructing neighborhoods from the bottom up: the case for resident-generated GIS. Environment and Planning B: Planning and Design 24: 533-554.

Wohlwill J.F., 1973. The study of behavioral development. Academic Press, Oxford.

Zyngier C., 2016. Paisagens urbanas possíveis: códigos compartilhados através dos Sistemas de Suporte ao Planejamento e do Geodesign. PhD Thesis, Federal University of Minas Gerais, Brazil. 